\title{
Sorption of perfluoroalkyl substances in sewage sludge
}

\author{
Jelena Milinovic $^{\mathrm{a}}$, Silvia Lacorte ${ }^{\mathrm{b}}$, Anna Rigol $^{\mathrm{a},{ }^{*}}$, Miquel Vidal $^{\mathrm{a}}$ \\ ${ }^{a}$ Department of Analytical Chemistry, University of Barcelona, Martí i Franquès 1-11, 08028 Barcelona, Spain \\ ${ }^{\mathrm{b}}$ Department of Environmental Chemistry, IDAEA-CSIC, Jordi Girona 18-26, 08034 Barcelona, Spain
}

\begin{abstract}
The sorption behaviour of three perfluoroalkyl substances (PFASs) (perfluorooctane sulfonate (PFOS), perfluorooctanoic acid (PFOA) and perfluorobutane sulfonate (PFBS)), was studied in sewage sludge samples. Sorption isotherms were obtained by varying initial concentrations of PFOS, PFOA and PFBS. The maximum values of the sorption solid-liquid distribution coefficients $\left(\mathrm{K}_{\mathrm{d}, \max }\right)$ varied by almost two orders of magnitude among the target PFASs: 140 $281 \mathrm{~mL} \mathrm{~g}^{-1}$ for PFOS, $30-54 \mathrm{~mL} \mathrm{~g}^{-1}$ for PFOA and $9-18 \mathrm{~mL} \mathrm{~g}^{-1}$ for PFBS. Freundlich and linear fittings were appropriate for describing the sorption behaviour of PFASs in the sludge samples, and the derived $\mathrm{K}_{\mathrm{F}}$ and $\mathrm{K}_{\mathrm{d} \text {,linear }}$ parameters correlated well. The hydrophobicity of the PFASs was the key parameter that influenced their sorption in sewage sludge. Sorption parameters and $\log \left(\mathrm{K}_{\mathrm{OW}}\right)$ were correlated, and for PFOS (the most hydrophobic compound), $\mathrm{pH}$ and $\mathrm{Ca}+\mathrm{Mg}$ status of the sludge controlled the variation in the sorption parameter values. Sorption reversibility was also tested from desorption isotherms, which were also linear. Desorption parameters were systematically higher than the corresponding sorption parameters (up to six-fold higher), thus indicating a significant degree of irreversible sorption, which decreased in the sequence PFOS $>$ PFOA $>$ PFBS.
\end{abstract}

Keywords: Perfluorooctanesulfonic acid, perfluorooctanoic acid, perfluorobutanesulfonic acid, sewage sludge, sorption, desorption.

\footnotetext{
* Corresponding author.

E-mail address: annarigol@ub.edu (A. Rigol).
} 


\section{Introduction}

Perfluoroalkyl substances (PFASs) comprise a large group of surface active compounds, characterized by a fully fluorinated hydrophobic carbon chain of varying length, to which different hydrophilic groups, such as sulfonic or carboxyl, are attached. PFASs are extremely resistant to hydrolysis and to thermal, microbiological and photolytic degradation because of their strong C-F bonds. Thus, they are widely used in many applications such as stain- and water-resistant textiles, food packaging, fire-extinguishing formulations, pesticides, paints, personal-care products and surfactants (Lau et al., 2007). In recent years, PFASs have attracted increasing public and scientific attention because of their high bioaccumulation potential, extreme persistence and toxic properties, such as their endocrine-disrupting activity and carcinogenesis (Kannan, 2011).

The most ubiquitous PFASs in the environment are perfluorooctane sulfonate (PFOS) and perfluorooctanoic acid (PFOA), since the degradation of PFAS precursors provides an additional source for these two compounds (Ellis et al., 2004). PFOS and PFOA have an eight-carbon chain structure and thus belong to the group of long-chain PFAS surfactants, with attached sulfonate and carboxyl group, respectively. In 2009, PFOS and its salts were added to the Stockholm Convention's list of persistent organic pollutants and hence their production was prohibited in the EU (UNEP, 2009). Nevertheless, a few industrialized countries still produce chemicals containing PFOS. Perfluorobutane sulfonate (PFBS) has recently been marketed as a homologous compound of PFOS in a variety of applications (OECD, 2006). PFBS has a four-carbon chain with a sulfonate hydrophilic group attached, which makes it a less bioaccumulative compound than PFOS (Newsted et al., 2008).

PFASs have been detected in wastewater and different wastewater products from wastewater treatment plants (WWTPs). This indicates that wastewater treatments cannot completely degrade PFASs, and thus a significant fraction can be found in the resulting 
sewage sludge (Sinclair and Kannan, 2006; Busch et al., 2010; Llorca et al., 2011). PFOS and PFOA were found in sludge samples from Denmark, Spain, Switzerland and USA in the ng g ${ }^{1}$ range, while higher concentrations (up to $\mu \mathrm{g} \mathrm{g}^{-1}$ ) were found in samples from China and Germany (Sun et al., 2011, Sun et al., 2012).

Both the total amount of PFASs and their sorption pattern in sludge are essential for evaluating the environmental risk associated with these organic pollutants. The sorption data of PFASs in sludge has scarcely been reported to date, and results indicated that sorption solid-liquid distribution coefficients $\left(\mathrm{K}_{\mathrm{d}}\right)$ may vary by up to three orders of magnitude, depending on the physicochemical characteristics of the PFASs, the sludge properties (digestion treatment) and the PFAS levels in wastewater. Moreover, the sorption mechanisms were not clearly determined due to the hydrophobic and hydrophilic nature of the PFASs (Ochoa-Herrera and Sierra-Alvarez, 2008; Zhou et al., 2010; Zhang et al., 2013). Other than the limited information about the sorption of PFASs in sludge, to the best of our knowledge, no data are available on the sorption reversibility of PFASs in sludge, although in situ $\mathrm{K}_{\mathrm{d}}$ data regarding the suspended matter of sludge and wastewater in contact are available (Arvaniti et al., 2012).

In order to gain a better understanding of the sorption mechanisms of PFASs in sewage sludge, we evaluated the sorption behaviour of the most environmentally relevant PFASs (PFOS, PFOA and PFBS) in sewage sludge samples with contrasting properties such as $\mathrm{pH}$, organic matter content, $\mathrm{Ca}$ and $\mathrm{Mg}$ content and dissolved organic carbon (DOC). Sorption and desorption tests were applied and the corresponding isotherms were built up in a wide range of initial concentrations of target compounds. Isotherms were fitted to appropriate sorption models (Freundlich and linear) and the sorption behaviour of each compound was quantitatively described by the derived fitting parameters. The effects of the sludge 
parameters, as well as of some main physicochemical properties of the PFASs, were considered in order to explain their sorption mechanisms.

\section{Materials and methods}

\subsection{Reagents and standards}

Milli-Q double deionized water $\left(18.2 \mathrm{M} \Omega \mathrm{cm}^{-1}\right)$ was obtained from a water purification system (USF PureLaB Plus, Spain). Water, ammonium acetate and acetonitrile, all of gradient grade for liquid chromatography, were supplied by Merck (Germany). Analytical standards of perfluorooctane sulfonate (PFOS, potassium salt, 98\%) and perfluorooctanoic acid (PFOA, 99.2\%) were purchased from Sigma-Aldrich (Germany) and perfluorobutane sulfonate (PFBS, tetrabutylammonium salt, 98\%) was purchased from Sigma-Aldrich (Switzerland). The main physicochemical properties of the PFASs selected for the sorption study are shown in Table 1 . The water solubility of the target PFASs increased by almost two orders of magnitude from PFOS to PFBS. Thus, it is expected that this latter PFAS would be transported into aqueous environments more easily than PFOS and PFOA. Since all three compounds have very low $\mathrm{pK}_{\mathrm{a}}$ values $\left(\mathrm{pK}_{\mathrm{a}}<0.14\right)$, they will be dissociated into their anionic species in the $\mathrm{pH}$ of the sludge samples. The octanol-water partition coefficient $\left(\mathrm{K}_{\mathrm{OW}}\right)$, which is a parameter widely used to estimate the hydrophobicity of compounds, was deduced from a SPARC partitioning model (Deng et al., 2012). The $\log \left(\mathrm{K}_{\mathrm{OW}}\right)$ values indicated that PFOS is more hydrophobic than PFOA and PFBS, which is consistent with the water solubility data.

Stock standard solutions of PFOS, PFOA and PFBS of $1000 \mathrm{mg} \mathrm{L}^{-1}$ were prepared individually in acetonitrile. Working solutions of PFASs for sorption and desorption experiments were prepared by the appropriate dilution of stock standards in acetonitrile. All 
solutions were stored at $-18^{\circ} \mathrm{C}$ in glass vials with polyethylene caps (Sigma-Aldrich, Germany).

Isotopically labelled standard solutions of sodium perfluoro- $1-\left[1,2,3,4,-{ }^{13} \mathrm{C}_{4}\right]$-octane sulfonate (MPFOS) and perfluoro-n-[1,2,3,4,- $\left.{ }^{13} \mathrm{C}_{4}\right]$-octanoic acid (MPFOA), both at concentrations of $50 \mu \mathrm{g} \mathrm{mL}^{-1}$, were purchased from Wellington Laboratories (Canada). Working solutions of MPFOS and MPFOA were prepared by 50-fold dilution of standard solutions in acetonitrile. The solutions were stored at $-18^{\circ} \mathrm{C}$ in $2-\mathrm{mL}$ chromatographic vials (Waters, USA).

\subsection{Sludge collection and characterisation}

Four sewage sludge samples (SL1 - SL4) were collected from WWTPs located in industrial areas in Catalonia, Spain. All the sludge samples originated from wastewater treatment processes that involved primary sedimentation, biological treatment (with nitrogen and phosphorous removal in the case of SL2 and SL3) and secondary sedimentation. The mixture of primary and secondary sludge was treated by gravity thickening, additional anaerobic digestion for SL1 and SL2, and dewatering by centrifugation (with additional pressure filtration for SL2). Fresh sludge samples were collected from the sludge tanks using precleaned amber glass pots.

An aliquot of approximately $1 \mathrm{~kg}$ of each sludge sample was dried at $40^{\circ} \mathrm{C}$ until constant weight was reached and then milled in agate mortar, homogenized by end-over-end shaking for $24 \mathrm{~h}$, and kept in polyethylene bottles at room temperature.

The dry matter of sludge samples was determined by drying $10 \mathrm{~g}$ of fresh sludge at $105^{\circ} \mathrm{C}$. The $\mathrm{pH}$ of fresh sludge samples was measured in Milli-Q water using a solution-tosludge ratio of $2.5 \mathrm{~mL} \mathrm{~g}^{-1}$. The organic matter $(\mathrm{OM})$ content was determined gravimetrically after combustion of $3 \mathrm{~g}$ of sludge at $550^{\circ} \mathrm{C}$. The organic carbon $(\mathrm{OC})$ content was determined using a Thermo EA 1108 elemental analyser (Thermo Scientific, Milan, Italy). OC was 
analysed in samples previously treated with $\mathrm{HCl}$ to eliminate carbonates and using tin capsules and $\mathrm{V}_{2} \mathrm{O}_{5}$ as an additive (ISO, 1995).

\subsection{Sorption and desorption experiments}

Three grams of dried sludge were suspended in an 80-mL polypropylene centrifuge tube with $30 \mathrm{~mL}$ of $0.01 \mathrm{~mol} \mathrm{~L}^{-1} \mathrm{CaCl}_{2}$ solutions (OECD, 2000). In addition, $0.03 \mathrm{~g}$ of $\mathrm{NaN}_{3}$ was added as a biodegradation inhibitor. The resulting suspension was end-over-end shaken for $24 \mathrm{~h}$ and then known volumes of the PFOS, PFOA or PFBS working solutions were added to the sludge suspensions to cover a range of initial concentrations from 160 to $3920 \mathrm{ng} \mathrm{mL}^{-1}$ for PFOS, from 35 to $1040 \mathrm{ng} \mathrm{mL}^{-1}$ for PFOA and from 30 to $650 \mathrm{ng} \mathrm{mL}^{-1}$ for PFBS in the solutions. The concentration ranges of the initial PFAS concentrations depended on the different physicochemical properties of the target compounds and the expected sequence of sorption according to their hydrophobic properties (Table 1). The resulting suspensions were shaken for $24 \mathrm{~h}$ at $60 \mathrm{rpm}$, centrifuged for $30 \mathrm{~min}$ at $9000 \mathrm{~g}$ (AJ2-HS, Beckman Coulter, USA) and the supernatants were decanted off. Desorption experiments were carried out for each compound by drying sludge residues $\left(40^{\circ} \mathrm{C}\right.$ for $\left.48 \mathrm{~h}\right)$ obtained from selected sorption scenarios, applying the same conditions as the previous sorption step, but with $30 \mathrm{~mL}$ of 0.01 mol L ${ }^{-1} \mathrm{CaCl}_{2}$ and without adding any PFAS.

Aliquots of $750 \mu \mathrm{L}$ of supernatants obtained from the sorption and desorption experiments were transferred into a 2 -mL chromatographic vial. Then, $10 \mu \mathrm{L}$ of the $1 \mu \mathrm{g} \mathrm{mL} \mathrm{L}^{-1}$ working solution of the internal standard (MPFOS or MPFOA) and $240 \mu \mathrm{L}$ of acetonitrile were added to the vial, and the PFASs were analysed by LC-MS/MS.

\subsection{Supernatant characterization}

For each sludge sample, blank sorption assays were also performed following the procedure explained above but without spiking with the target PFASs. Aliquots of the 
supernatants were used to characterize the contact solution after sorption in terms of dissolved organic carbon (DOC) and cationic composition ( $\mathrm{Ca}$ and $\mathrm{Mg})$.

The DOC content was measured using a Total Organic Carbon analyser (Shimadzu TOC-5000A) (Shimadzu, Japan) with a previous acidification with $\mathrm{HCl}$ to a $\mathrm{pH}$ of 3 to remove the carbonates in solution. The total concentration of cations $(\mathrm{Ca}$ and $\mathrm{Mg}$ ) was determined by inductively coupled plasma optical emission spectrometry (ICP-OES) (Thermo-Jarrell Ash 25 and Perkin Elmer Optima 3200 RL, USA). The following emission lines were used (nm): Ca: 315.887 and 317.933, Mg: 279.077 and 285.213. The detection limits of ICP-OES were $0.1 \mathrm{mg} \mathrm{L}^{-1}$ for $\mathrm{Ca}$ and $\mathrm{Mg}$.

\subsection{LC-MS/MS analysis of PFOS, PFOA and PFBS}

The PFOS, PFOA and PFBS concentrations were determined using liquid chromatography (LC) coupled to tandem mass spectrometry (MS/MS). The analytical system consisted of an Acquity LC connected to a Triple Quadrupole Detector (TQD) (Waters, USA). An Eclipse XDB-C18 column $(150 \times 2.1 \mathrm{~mm}, 5 \mu \mathrm{m}$ particle size) (Agilent, USA) was connected to a $\mathrm{C}_{18}$ pre-column.

Chromatographic separation conditions were adapted from Gómez-Canela et al. (2012). In short, a binary gradient mobile phase consisting of acetonitrile (A) and $3 \mathrm{mM}$ ammonium acetate (B) was used for analysis. Gradient elution started at 25\% A and $75 \%$ B for $1 \mathrm{~min}$, increased to $85 \% \mathrm{~A}$ in $5 \mathrm{~min}$, then to $100 \% \mathrm{~A}$ in $30 \mathrm{~s}$ and maintained thus for $30 \mathrm{~s}$. The initial conditions ( $25 \% \mathrm{~A}$ and $75 \% \mathrm{~B}$ ) were reached again in the next $1 \mathrm{~min}$, and the system was stabilized over the following $4 \mathrm{~min}$. The flow rate was set at $0.3 \mathrm{~mL} \mathrm{~min}^{-1}$ and the injection volume was $10 \mu \mathrm{L}$. The main working parameters for the MS detector were set as follows: capillary voltage of $2.8 \mathrm{kV}$, cone gas flow of $50 \mathrm{~L} \mathrm{~h}^{-1}$, desolvation gas flow of $100 \mathrm{~L}$ $\mathrm{h}^{-1}$, source temperature of $120^{\circ} \mathrm{C}$ and desolvation temperature of $400^{\circ} \mathrm{C}$. Nitrogen $(99.9 \%)$ and argon (99.9\%) were used as cone and collision gases, respectively. 
Analysis of the PFASs was performed under negative electrospray ionization mode. Transitions from precursor to product ions, cone voltage and collision energy of multiple reaction monitoring used for the LC-MS/MS analysis of the PFASs are summarized in Supplementary Information (Table S1). The dwell time established for each transition was 0.1 $\mathrm{s}$ and the interscan delay was set at $10 \mathrm{~ms}$. Compounds were identified by their most abundant transitions of precursor and product ions (m/z) and retention times (Fig. 1). Quantification peaks of PFBS, PFOS and MPFOS at $\mathrm{m} / \mathrm{z} 80$ corresponded to the $\left[\mathrm{SO}_{3}\right]^{-}$fragment, the PFOA peak at $\mathrm{m} / \mathrm{z} 369$ was attributed to the $\left[\mathrm{C}_{7} \mathrm{~F}_{15}\right]^{-}$chain fragment and the MPFOA peak at $\mathrm{m} / \mathrm{z}$ 372 was due to the fragment $\left[\mathrm{C}_{4}{ }^{13} \mathrm{C}_{3} \mathrm{~F}_{15}\right]^{-}$. In the case of PFOS, two peaks were observed: one with a higher retention time (at approximately $4.5 \mathrm{~min}$ ) that was attributed to the most abundant and hydrophobic linear form of the compound, and the other (at around $4.3 \mathrm{~min}$ ) to the branched isomer (Langlois and Oehme, 2006). The total PFOS concentration was calculated by taking into account the sum of two peak areas.

Quantification was based on a seven-point calibration curve with a PFAS concentration range of 1 to $200 \mathrm{ng} \mathrm{mL}^{-1}$. Regression coefficients were always higher than 0.99. Internal standard quantification was performed using MPFOS to quantify PFOS and MPFOA to quantify PFOA and PFBS. The detection limits of the method ( $\mathrm{LOD}_{\text {method }}$ ) were determined for each PFAS as the concentration with a signal-to-noise ratio of three. The values obtained, expressed with respect to the solution obtained from sorption experiments, were $0.1 \mathrm{ng} \mathrm{mL}{ }^{-1}$ for PFOS and PFOA and $0.3 \mathrm{ng} \mathrm{mL}^{-1}$ for PFBS.

\subsection{Quality control}

In order to minimize the contamination of samples, Teflon (polytetrafluoroethylene) materials were not used in the experiments. Sample blanks were run in parallel to check that the sludge samples did not contribute to the target compound concentrations measured in the supernatants. Furthermore, control tests were run in the same tubes and conditions as used for 
the sorption tests (using $70 \mathrm{ng} \mathrm{mL}^{-1}$ PFOS, $40 \mathrm{ng} \mathrm{mL}^{-1}$ PFOA, $70 \mathrm{ng} \mathrm{mL}^{-1} \mathrm{PFBS}, 1.7 \mathrm{ng} \mathrm{mL}{ }^{-1}$ MPFOS and $1.7 \mathrm{ng} \mathrm{mL}^{-1}$ MPFOA solutions) and the results showed that there were no significant compound losses due to PFAS sorption in the material used or degradation. Reproducibility of the method, calculated as the relative standard deviation of the triplicate analyses of samples was reasonable, i.e. in the range of 5\%-15\%.

\subsection{Quantification of sorption and desorption parameters}

The sorption solid-liquid distribution coefficient, $\mathrm{K}_{\mathrm{d}}\left(\mathrm{mL} \mathrm{g}^{-1}\right)$, was calculated as the ratio between the concentration of the target compound (PFOS, PFOA or PFBS) sorbed in the sludge, $\mathrm{C}_{\mathrm{s}}\left(\mathrm{ng} \mathrm{g}^{-1}\right)$, and its concentration in the aqueous phase at the equilibrium, $\mathrm{C}_{\mathrm{eq}}\left(\mathrm{ng} \mathrm{mL}^{-}\right.$ $1)$ :

$\mathrm{K}_{\mathrm{d}}=\frac{\mathrm{C}_{\mathrm{s}}}{\mathrm{C}_{\mathrm{eq}}}$

$\mathrm{C}_{\mathrm{eq}}$ values were directly determined by LC-MS/MS and the corresponding concentrations of PFASs sorbed by the sludge, whereas $\mathrm{C}_{\mathrm{s}}$ was calculated by the following equation:

$\mathrm{C}_{\mathrm{s}}=\frac{\left(\mathrm{C}_{\mathrm{in}}-\mathrm{C}_{\mathrm{eq}}\right) \cdot \mathrm{V}}{\mathrm{m}_{\mathrm{SL}}}$

where $\mathrm{C}_{\text {in }}\left(\mathrm{ng} \mathrm{mL} \mathrm{L}^{-1}\right)$ corresponds to the initial concentration of PFAS added to the sludge suspension, $\mathrm{V}(\mathrm{mL})$ is the volume of solution and $\mathrm{m}_{\mathrm{SL}}(\mathrm{g})$ refers to the dry mass of the sludge sample.

The organic carbon distribution coefficient, $\mathrm{K}_{\mathrm{OC}}\left(\mathrm{mL} \mathrm{g}^{-1}\right)$, was calculated from the $\mathrm{K}_{\mathrm{d}}$ values obtained, according to the following equation:

$\mathrm{K}_{\mathrm{OC}}=\frac{\mathrm{K}_{\mathrm{d}}}{\mathrm{F}_{\mathrm{OC}}}$

where $\mathrm{F}_{\mathrm{OC}}$ is the fraction of organic carbon in the sludge, expressed as grams of organic carbon per gram of sludge. 
As with $\mathrm{K}_{\mathrm{d}}$ (Eq. 1), the desorption solid-liquid distribution coefficient, $\mathrm{K}_{\mathrm{d} \text {,des }}\left(\mathrm{mL} \mathrm{g}^{-1}\right)$, was calculated as follows:

$\mathrm{K}_{\mathrm{d}, \mathrm{des}}=\frac{\mathrm{C}_{\mathrm{s}, \mathrm{des}}}{\mathrm{C}_{\mathrm{eq}, \mathrm{des}}}$

where $\mathrm{C}_{\mathrm{s} \text {,des }}\left(\mathrm{ng} \mathrm{g}^{-1}\right)$ and $\mathrm{C}_{\mathrm{eq} \text {,des }}\left(\mathrm{ng} \mathrm{mL}^{-1}\right)$ are, respectively, the PFAS concentration in the solid phase and the liquid phase after the desorption experiment. $\mathrm{C}_{\mathrm{eq}, \mathrm{des}}$ values were directly determined by LC-MS/MS, whereas $\mathrm{C}_{\mathrm{s}, \text { des }}$ was calculated as the difference between the initial PFAS concentration in the sludge residue resulting from the sorption experiment, $\mathrm{C}_{\mathrm{in}, \mathrm{des}}(\mathrm{ng} \mathrm{g}$ ${ }^{1}$ ), and the PFAS desorbed referred to the mass of sludge, as follows:

$\mathrm{C}_{\mathrm{s}, \mathrm{des}}=\mathrm{C}_{\mathrm{in}, \mathrm{des}}-\frac{\mathrm{C}_{\mathrm{eq}, \mathrm{des}} \cdot \mathrm{V}}{\mathrm{m}_{\mathrm{SL}}}$

$\mathrm{C}_{\mathrm{in} \text {,des }}$ is $\mathrm{C}_{\mathrm{s}}$, corrected, when required, by the amount of PFAS present in the residual volume of solution $\left(\mathrm{C}_{\mathrm{eq}} \cdot \mathrm{V}_{\text {res }}\right)$ that remained in the sludge after the sorption experiment:

$\mathrm{C}_{\mathrm{in}, \mathrm{des}}=\mathrm{C}_{\mathrm{s}}+\frac{\mathrm{C}_{\mathrm{eq}} \cdot \mathrm{V}_{\mathrm{res}}}{\mathrm{m}_{\mathrm{SL}}}$

Finally, the desorption yield, D (\%), was calculated from the ratio between the amount of PFAS desorbed and the amount of PFAS present in the sludge prior to the desorption experiment, as follows:

$\mathrm{D}(\%)=\frac{\mathrm{C}_{\text {eq,des }} \cdot \mathrm{V}}{\mathrm{C}_{\mathrm{in}, \mathrm{des}} \cdot \mathrm{m}_{\text {soil }}} \cdot 100$

\subsection{Fitting of sorption and desorption isotherms}

Sorption and desorption isotherms were fitted to Freundlich and linear models. The Freundlich sorption and desorption isotherms are quantitatively described by the following equations, respectively:

$$
\begin{aligned}
& C_{s}=K_{F} \cdot\left(C_{e q}\right)^{N} \\
& C_{s, \text { des }}=K_{F, \text { des }} \cdot\left(C_{\text {eq,des }}\right)^{N_{\text {des }}}
\end{aligned}
$$




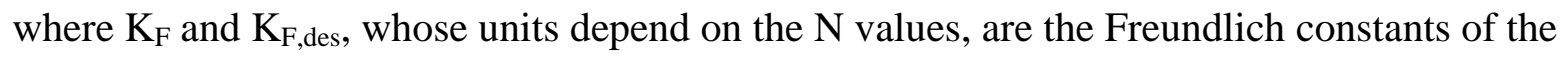
respective processes and express the affinity of a compound to a given solid sorbent, and $\mathrm{N}$ is an empirical parameter that describes the degree of isotherm nonlinearity. When $\mathrm{N}$ is approximately equal to 1, the Freundlich model can be assumed as linear, and in that case the value of $K_{F}$ is close to a value of $K_{d}$ (and $K_{F, \text { des }}$ to a value of $K_{d, \text { des }}$ ), valid for the whole concentration range tested.

The $\mathrm{K}_{\mathrm{F}}$ and $\mathrm{N}$ parameters of the Freundlich model were calculated using the Solver function in Microsoft Excel ${ }^{\mathrm{TM}}$, by minimizing a residual root mean square error (RMSE), which for $m$ experimental data points and $p$ adjustable fitting parameters is defined by the following equation (Kinniburgh, 1986):

$\operatorname{RMSE}=\left(\frac{\mathrm{RSS}}{m-p}\right)^{1 / 2}$

where RSS is the residual sum of squares, which for $m$ experimental data is given by the following equation:

$\mathrm{RSS}=\sum_{i=1}^{\mathrm{m}} \frac{\left(\mathrm{C}_{\mathrm{s}, \mathrm{exp}, \mathrm{i}}-\mathrm{C}_{\mathrm{s}, \mathrm{cal}, \mathrm{i}}\right)^{2}}{\left(\mathrm{C}_{\mathrm{s}, \mathrm{cal}, \mathrm{i}}\right)^{2}}$

where $\mathrm{C}_{\mathrm{s}, \exp , \mathrm{i}}$ and $\mathrm{C}_{\mathrm{s}, \mathrm{cal}, \mathrm{i}}$ are the experimental and calculated sorbed concentration, respectively. The parameters of the Freundlich model for the desorption isotherms were calculated in the same way from the $\mathrm{C}_{\mathrm{s}, \mathrm{des}, \text { exp }, \mathrm{i}}$ and $\mathrm{C}_{\mathrm{s}, \mathrm{des}, \mathrm{cal}, \mathrm{i}}$ data.

Sorption and desorption isotherms could also be fitted to a linear equation in most cases, described by a constant slope of $\mathrm{C}_{\mathrm{s}} v s \mathrm{C}_{\mathrm{eq}}$ and of $\mathrm{C}_{\mathrm{s}, \mathrm{des}} v s \mathrm{C}_{\mathrm{eq}, \mathrm{des}}$ in the entire concentration range analysed. In these cases, a best-estimate $K_{d}$ value, valid for the whole concentration range tested $\left(\mathrm{K}_{\mathrm{d} \text {,linear }}\right.$ and $\left.\mathrm{K}_{\mathrm{d} \text {,des,linear }}\right)$, was deduced directly from the slope of the isotherms. 


\section{Results and discussion}

\subsection{Properties of sludge samples}

The main properties of the sludge samples are summarized in Table 2. Samples SL1 and SL2 were slightly basic with a similar pH; SL3 was neutral; and sludge sample SL4 was slightly acidic. The OM content ranged from $62 \%$ to $77 \%$. The lower OM content of SL1 and SL2 samples may have been the result of the anaerobic digestion treatment performed on these samples. The DOC was not significantly correlated to either OC or OM, indicating the different characteristics of organic matter, mainly solubility, in the examined sludge samples. In contrast, the $\mathrm{Ca}+\mathrm{Mg}$ content was inversely correlated to $\mathrm{pH}\left(\mathrm{R}^{2}=0.95\right)$ and directly correlated to DOC $\left(\mathrm{R}^{2}=0.95\right)$. The DOC and $\mathrm{pH}$ values of sludge samples were also inversely correlated $\left(\mathrm{R}^{2}=0.94\right)$, which confirms that higher amounts of dissolved organic matter normally implies lower pH values, as observed in a previous work (Milinovic et al., 2014).

\subsection{Sorption behaviour of PFOS, PFOA and PFBS in sludge samples}

\subsubsection{Sorption isotherms of PFOS, PFOA and PFBS}

The sorption isotherms of PFOS, PFOA and PFBS in the SL1 sludge sample are shown in Figure 2. Similarly shaped isotherms were obtained for the rest of the sludge samples, as shown in the Supplementary Information (Figs. S1-S3). Sorption isotherms $\left(\mathrm{C}_{\mathrm{s}} v s\right.$. $\mathrm{C}_{\mathrm{eq}}$ ) of all three compounds followed a linear pattern for the concentration ranges studied. This was also observed with the $\mathrm{K}_{\mathrm{d}} v s . \mathrm{C}_{\mathrm{s}}$ isotherms, which showed near-to-zero slopes. Many organic substances follow this type of isotherm (Hinz, 2001; Higgins and Luthy, 2006), especially in porous materials such as sludge, and this makes PFAS sorption in inner sorption sites possible (Ochoa-Herrera and Sierra-Alvarez, 2008).

Consistent with linear-shaped isotherms, the experimentally obtained $\mathrm{K}_{\mathrm{d} \text {,min }}$ and $\mathrm{K}_{\mathrm{d} \text {,max }}$ values were quite similar, although $\mathrm{K}_{\mathrm{d} \text {,max }}$ were often lower than two-fold $\mathrm{K}_{\mathrm{d} \text {,min }}$ values (see Table 3). The narrow interval of results in the sludge samples obtained for each compound 
suggest that the effect of the sludge origin on the sorption of PFASs was much lower than the effect of the PFAS, partly due to their similar OM content. On the other hand, $\mathrm{K}_{\mathrm{d}}$ differences were higher with respect to the PFASs. When $\mathrm{K}_{\mathrm{d}, \max }$ values were compared, a clear sequence of decreasing sorption was noticed from PFOS (140 - $\left.281 \mathrm{~mL} \mathrm{~g}^{-1}\right)$ to PFOA (30 - $\left.54 \mathrm{~mL} \mathrm{~g}^{-1}\right)$, with PFBS presenting the lowest values $\left(7-18 \mathrm{~mL} \mathrm{~g}^{-1}\right)$.

Despite the narrow $\mathrm{K}_{\mathrm{d} \text {,min }}-\mathrm{K}_{\mathrm{d} \text {,max }}$ ranges, fitting the sorption isotherms to simple sorption equations allowed us to suggest the best-estimate values of the $\mathrm{K}_{\mathrm{d}}$ for the PFASsludge combinations examined. The linearity of the sorption isotherms was quantitatively confirmed by fitting parameter $\mathrm{N}$ of the Freundlich model, which was close to 1 (Table 3 ). Moreover, the $\mathrm{K}_{\mathrm{d}}$ values derived from the slope of the $\mathrm{C}_{\mathrm{s}} v s . \mathrm{C}_{\mathrm{eq}}$ linear equation $\left(\mathrm{K}_{\mathrm{d} \text {,linear }}\right)$ for the three PFASs correlated well with the $K_{F}$ parameter values $\left(K_{F}=0.94(0.06) \cdot K_{d, \text { linear }} ; R^{2}=\right.$ $0.96)$.

Experimental data for PFOS were in good agreement with previously reported results, in which the $\mathrm{K}_{\mathrm{d}}$ range for PFOS was $30-280 \mathrm{~mL} \mathrm{~g}^{-1}$ (Ochoa-Herrera and Sierra-Alvarez, 2008; Zhang et al., 2013). However, the values obtained were much lower than those observed by other authors (Yu et al., 2009; Zhou et al., 2010; Arvaniti et al., 2012; Arvaniti et al., 2014), which might be attributed to the different characteristics of the sludge samples and the experimental conditions used to derive the $\mathrm{K}_{\mathrm{d}}$ values. $\mathrm{K}_{\mathrm{OC}}$ values of PFOS obtained in the present work ranged from 411 to $706 \mathrm{~mL} \mathrm{~g}^{-1}$, which were very similar to some $\mathrm{K}_{\mathrm{OC}}$ values previously reported (Higgins and Luthy, 2006; 3M, 2000 cited in Yu et al., 2009; Milinovic et al., 2015). However, higher $\mathrm{K}_{\mathrm{OC}}$ values were obtained by Yu et al. (2009) and Arvaniti et al. (2014), which was in accordance with the higher $K_{d}$ values obtained by these authors. At the $\mathrm{pH}$ of the sludge, PFASs are deprotonated, and thus the anionic form predominates. This would lead to electrostatic repulsion to the negatively charged sludge surface, although it is also possible that there is electrostatic interaction with the sludge surface through $\mathrm{Ca} / \mathrm{Mg}$ ion 
bridge bonds as pointed out in previous works (Zhou et al., 2010; Arvaniti et al., 2014). This was confirmed by the excellent correlation between the PFOS sorption parameters and the $\mathrm{Ca}+\mathrm{Mg}$ content in the supernatants after the sorption process (for instance, $\mathrm{K}_{\mathrm{F}}=1.04(0.05)$. $\left.(\mathrm{Ca}+\mathrm{Mg})_{\text {solution}} ; \mathrm{R}^{2}=0.99\right)$. Arvaniti et al. (2014) also showed a similar slope, around 1 , between $\mathrm{K}_{\mathrm{d}}$ and $\mathrm{Ca}$ concentration. In addition, PFOS sorption parameters also showed an inverse correlation with $\mathrm{pH}\left(\mathrm{R}^{2}=0.96\right)$ in the range between 6.1 and 8.4 , which was already found by Arvaniti et al. (2014) in the same range of $\mathrm{pH}$ values and by Zhou et al. (2010) in a wider $\mathrm{pH}$ range (between 3 and 9.5). At lower $\mathrm{pH}$, the concentration of positive charges increases in the sludge surface favouring the interaction of PFOS that exists as anionic species in the solution.The PFOA showed a lower sorption affinity for the sludge than PFOS, with consistently lower $\mathrm{K}_{\mathrm{F}}$ and $\mathrm{K}_{\mathrm{d} \text {,linear }}$ values than those for PFOS. These results were consistent with previous results (Zhang et al., 2013), in which $\mathrm{K}_{\mathrm{d}}$ values for PFOA ranged from 13 - 68 $\mathrm{mL} \mathrm{g}^{-1}$, while $\mathrm{K}_{\mathrm{d}}$ values up to one order of magnitude higher were obtained by other authors (Yu et al., 2009; Zhou et al., 2010; Arvaniti et al., 2012; Arvaniti et al., 2014), as already discussed for PFOS. However, our results agreed with the finding that PFOA had a lower sorption affinity for sludge than PFOS. The lower sorption of PFOA can be explained by its lower hydrophobicity, as deduced by its $\operatorname{lower} \log \left(\mathrm{K}_{\mathrm{OW}}\right)$ due to the change in the hydrophilic group and the lower number of C-F bonds. $\mathrm{K}_{\mathrm{OC}}$ of PFOA ranged from 75 to $219 \mathrm{~mL} \mathrm{~g}^{-1}$. As for PFOS, these values were very similar to some values previously reported (Higgins and Luthy, 2006; DuPont, 2003 cited in Yu et al., 2009; Milinovic et al., 2015), but much lower than those obtained by $\mathrm{Yu}$ et al. (2009) and Arvaniti et al. (2014). In contrast, $\mathrm{pH}$ and $\mathrm{Ca}+\mathrm{Mg}$ content in the supernatants after sorption did not have a clear effect in the sorption of PFAS. In Arvaniti et al. (2014) the effect of $\mathrm{pH}$ and $\mathrm{Ca}$ concentration in sorption was also less pronounced for PFOA than for PFOS. 
The sorption affinity of PFBS was the lowest among the PFASs examined. Similarly, low values for $\mathrm{K}_{\mathrm{d}}\left(10-50 \mathrm{~mL} \mathrm{~g}^{-1}\right)$ were reported for PFBS sorption in sludge, although the data reported were very limited (Zhang et al., 2013). Koc values ranged from 19 to $46 \mathrm{~mL} \mathrm{~g}^{-1}$, similar to values obtained in soils (Milinovic et al., 2015). The lower sorption affinity of PFBS compared to PFOS and PFOA can be explained by the lower hydrophobicity of the former, as demonstrated by the low value of its $\log \left(\mathrm{K}_{\mathrm{OW}}\right)$ and explained by its shorter carbon chain. The relative low and constant values of $\mathrm{K}_{\mathrm{F}}$ and $\mathrm{K}_{\mathrm{d} \text {,linear }}$ prevented the observation of any significant correlation with sludge properties.

To confirm that the hydrophobicity of the PFASs governed their sorption, $\mathrm{K}_{\mathrm{d} \text {,linear }} v s$. $\log \left(\mathrm{K}_{\mathrm{OW}}\right)$ correlations were examined for the three compounds in each sludge sample. All correlations obtained had regression coefficients over 0.99 , indicating that the main sorption mechanism is the hydrophobic interaction between the perfluorinated chain of the PFAS and the organic matter of the sludge.

\subsubsection{Desorption isotherms of PFOS, PFOA and PFBS}

Figure 3 shows, as an example, the sorption and desorption isotherms of PFOS, PFOA and PFBS in the SL2 sludge sample, while the remaining desorption isotherms are shown in the Supplementary Information (Figs. S4-S7). The desorption isotherms followed a linear pattern for the three compounds, as already observed in the sorption stage. Experimentally obtained desorption distribution coefficients, $\mathrm{K}_{\mathrm{d}, \mathrm{des} \text {,min }}$ and $\mathrm{K}_{\mathrm{d}, \mathrm{des} \text {,max }}$, varied within narrow ranges for every PFAS (see Table 4). The sequence of values observed were also in line with the previous sorption stage, as $\mathrm{K}_{\mathrm{d} \text {,des }}$ values decreased in the order PFOS > PFOA > PFBS, although $\mathrm{K}_{\mathrm{d}, \mathrm{des}}$ values for PFOA and PFBS were closer to each other than those of the previous sorption stage.

Desorption isotherm linearity was confirmed by the $\mathrm{N}_{\text {des }}$ parameter values, which did not differ from 1. Experimental data fitted well to the Freundlich and linear equations, with 
regression coefficients higher than 0.97 for all sludge-compound combinations. As with the sorption results, here the $\mathrm{K}_{\mathrm{d} \text {,des }}$ and $\mathrm{K}_{\mathrm{F} \text {,des }}$ of the PFASs were also similar in all samples and correlated well $\left(\mathrm{K}_{\mathrm{F} \text {,des }}=1.5(0.1) \cdot \mathrm{K}_{\mathrm{d} \text {,des,linear }} ; \mathrm{R}^{2}=0.93\right)$, although $\mathrm{K}_{\mathrm{F} \text {.des }}$ for PFOS appeared to be systematically higher than the respective $\mathrm{K}_{\mathrm{d} \text {,des,linear }}($ Table 4 ).

Desorption parameters were generally higher than the respective sorption parameters, with $\mathrm{K}_{\mathrm{F}}$ and $\mathrm{K}_{\mathrm{d}}$ ratios close to 6 (see Table 4). This indicated that the sorption of PFASs was partially irreversible. This was confirmed by the desorption yields, which are summarized in Figure 4. Desorption yields for PFOS were lower than $4 \%$ in all samples; this confirms that this compound was irreversibly sorbed to the sludge, whereas desorption yields of PFOA and PFBS were much higher (15\%-19\% and 18\%-27\%, respectively). Therefore, PFOS showed both the highest sorption and the highest sorption irreversibility, which can also be attributed to the fact that it has the lowest water solubility and highest hydrophobicity among the PFASs examined. In terms of the sorption data, $\mathrm{K}_{\mathrm{d}, \mathrm{des}}$ and $\log \left(\mathrm{K}_{\mathrm{OW}}\right)$ correlated well for the three PFASs in each sludge sample $\left(\mathrm{R}_{2}>0.98\right)$; this confirms that PFAS hydrophobicity was a key factor governing the sorption and subsequent sorption reversibility of the PFASs in sludge samples.

\section{Conclusions}

Sorption of PFOS, PFOA and PFBS in sewage sludge was linear. The dominant mechanism was the hydrophobic interaction between the perfluorinated carbon chain and the organic matter of the sludge, with a potential role for $\mathrm{Ca}-\mathrm{Mg}$ ion bridges in overcoming electrostatic repulsion at sludge surface sites. In agreement with the $\log \left(\mathrm{K}_{\mathrm{OW}}\right)$ sequence, the sorption affinity of the PFASs decreased in the order PFOS > PFOA > PFBS, while sorption irreversibility was also the highest for PFOS. Further studies, including other PFASs and sludge samples with varying $\mathrm{pH}$ and $\mathrm{OM}$ content, will make it possible to confirm the 
sorption mechanism of PFASs in sewage sludge, that is, the role of organic matter and the $\mathrm{Ca}+\mathrm{Mg}$ status in PFAS sorption.

\section{Acknowledgements}

This research was funded by the Spanish government (CICYT, contracts CTM 200801147 / TECNO and CTM 2011-27211) and the Generalitat de Catalunya (2009SGR1188). Jelena Milinovic thanks the Catalan government for a PhD fellowship (2010FI_B 00513). We thank Cristian Gómez, Roser Chaler and Dori Fanjul for the assistance with the LC-MS/MS analysis.

\section{References}

Arvaniti, O.S., Ventouri, E.I., Stasinakis, A.S., Thomaidis, N.S., 2012. Occurrence of different classes of perfluorinated compounds in Greek wastewater treatment plants and determination of their solid-water distribution coefficients. J. Hazard. Mater. 239-240, 24-31.

Arvaniti, O.S., Andersen, H.R., Thomaidis, N.S., Stasinakis, A.S., 2014. Sorption of perfluorinated compounds onto different types of sewage sludge and assessment of its importance during wastewater treatment. Chemosphere 111, 405-411.

Busch, J., Ahrens, L., Sturm, R., Ebinghaus, R., 2010. Polyfluoroalkyl compounds in landfill leachates. Environ. Pollut. 158, 1467-1471.

Deng, S., Zhang, Q., Nie, Y., Wei, H., Wang, B., Huang, J., Yu, G., Xing, B., 2012. Sorption mechanisms of perfluorinated compounds on carbon nanotubes. Environ. Pollut. 168, 138-144. 
Ellis, D.A., Martin, J.W., De Silva, A.O., Mabury, S.A., Hurley, M.D., Andersen, M.P.S., Wallington, T.J., 2004. Degradation of fluorotelomer alcohols: a likely atmospheric source of perfluorinated carboxyl acids. Environ. Sci. Technol. 38, 3316-3321.

Gómez-Canela, C., Barth, J.A.C., Lacorte, S., 2012. Occurrence and fate of perfluorinated compounds in sewage sludge from Spain and Germany. Environ. Sci. Pollut. R. 19, 4109-4119.

Higgins, C.P., Luthy, R.G., 2006. Sorption of Perfluorinated Surfactants on Sediments. Environ. Sci. Technol. 40, 7251-7256.

Hinz, C., 2001. Description of sorption data with isotherm equations. Geoderma 99, 225-243.

ISO, 1995. Soil quality. Determination of organic and total carbon after dry combustion (elementary analysis). International Organisation for Standardisation, ISO 10694.

Kannan, K., 2011. Perfluoroalkyl and polyfluoroalkyl substances: current and future perspectives. Environ. Chem. 8, 333-338.

Kinniburgh, D.G., 1986. General purpose adsorption isotherms. Environ. Sci. Technol. 20, 895-904.

Langlois, I., Oehme, M., 2006. Structural identification of isomers present in technical perfluorooctane sulfonate by tandem mass spectrometry. Rapid Commun. Mass Sp. 20, 844-50.

Lau, C., Anitole, K., Hodes, C., Lai, D., Pfahles-Hutchens, A., Seed, J., 2007. Perfluoroalkyl acids: a review of monitoring and toxicological findings. Toxicol. Sci. 99, 366-394.

Llorca, M., Farré, M., Picó, Y., Barceló, D., 2011. Analysis of perfluorinated compounds in sewage sludge by pressurized solvent extraction followed by liquid chromatographymass spectrometry. J. Chromatogr. A 1218, 4840-4846. 
Milinovic, J., Vidal, M., Lacorte, S., Rigol, A., 2014. Leaching of heavy metals and alkylphenolic compounds from fresh and dried sewage sludge. Environ. Sci. Pollut. Res. 21, 2009-2017.

Milinovic, J., Lacorte, S., Vidal, M., Rigol, A., 2015. Sorption behaviour of perfluoroalkyl substances in soils. Sci. Total Environ. 511, 63-71.Newsted, J.L., Beach, S.A., Gallagher, S.P., Giesy, J.P., 2008. Acute and chronic effects of perfluorobutane sulfonate (PFBS) on the mallard and northern bobwhite quail. Arch. Environ. Con. Tox. $54,535-545$

Ochoa-Herrera, V., Sierra-Alvarez, R., 2008. Removal of perfluorinated surfactants by sorption onto granular activated carbon, zeolite and sludge. Chemosphere 72, 15881593.

OECD, 2000. Organization for Economic Co-operation and Development. Guideline for the testing of chemicals: Adsorption-desorption using a batch equilibrium method.

\section{OECD/OCDE 106}

OECD, 2006. Organization for Economic Co-operation and Development. Results of the 2006 OECD survey on production and use of PFOS, PFAS, PFOA, PFCA, their related substances and products/mixtures containing these substances. OECD Environment, Health and Safety Publications, Series on Risk Management.

UNEP, 2009. Stockholm Convention on Persistent Organic Pollutants (POPs). Listing of perfluorooctane sulfonic acid, its salts and perfluorooctane sulfonyl fluoride, UNEPPOPS-COP.4-SC-4/17, Geneva, Stockholm Convention, UNEP. Available in [http://chm.pops.int/TheConvention/ThePOPs/TheNewPOPs/tabid/2511/Default.aspx].

Sinclair, E., Kannan, K., 2006. Mass loading and fate of perfluoroalkyl surfactants in wastewater treatment plants. Environ. Sci. Technol. 40, 1408-1414. 
Sun, H., Gerecke, A.C., Giger, W., Alder, A.C., 2011. Long-chain perfluorinated chemicals in digested sewage sludges in Switzerland. Environ. Pollut. 159, 654-662.

Sun, H., Zhang, X., Wang, L., Zhang, T., Li, F., He, N., Alder, A.C., 2012. Perfluoroalkyl compounds in municipal WWTPs in Tianjin, China-concentrations, distribution and mass flow. Environ. Sci. Pollut. Res. 19(5), 1405-1415.

Yu, J., Hu, J., Tanaka, S., Fujii, S., 2009. Perfluorooctane sulfonate (PFOS) and perfluorooctanoic acid (PFOA) in sewage treatment plants. Water Res. 43, 2399-2408.

Zhang, C., Yan, H., Li, F., Hu, X., Zhou, Q., 2013. Sorption of short- and long-chain perfluoroalkyl surfactants on sewage sludges. J. Hazard. Mater. 260, 689-699.

Zhou, Q., Deng, S., Zhang, Q., Fan, Q., Huang, J., Yu, G., 2010. Sorption on perfluorooctane sulfonate and perfluorooctanoate on activated sludge. Chemosphere 81, 453-458. 

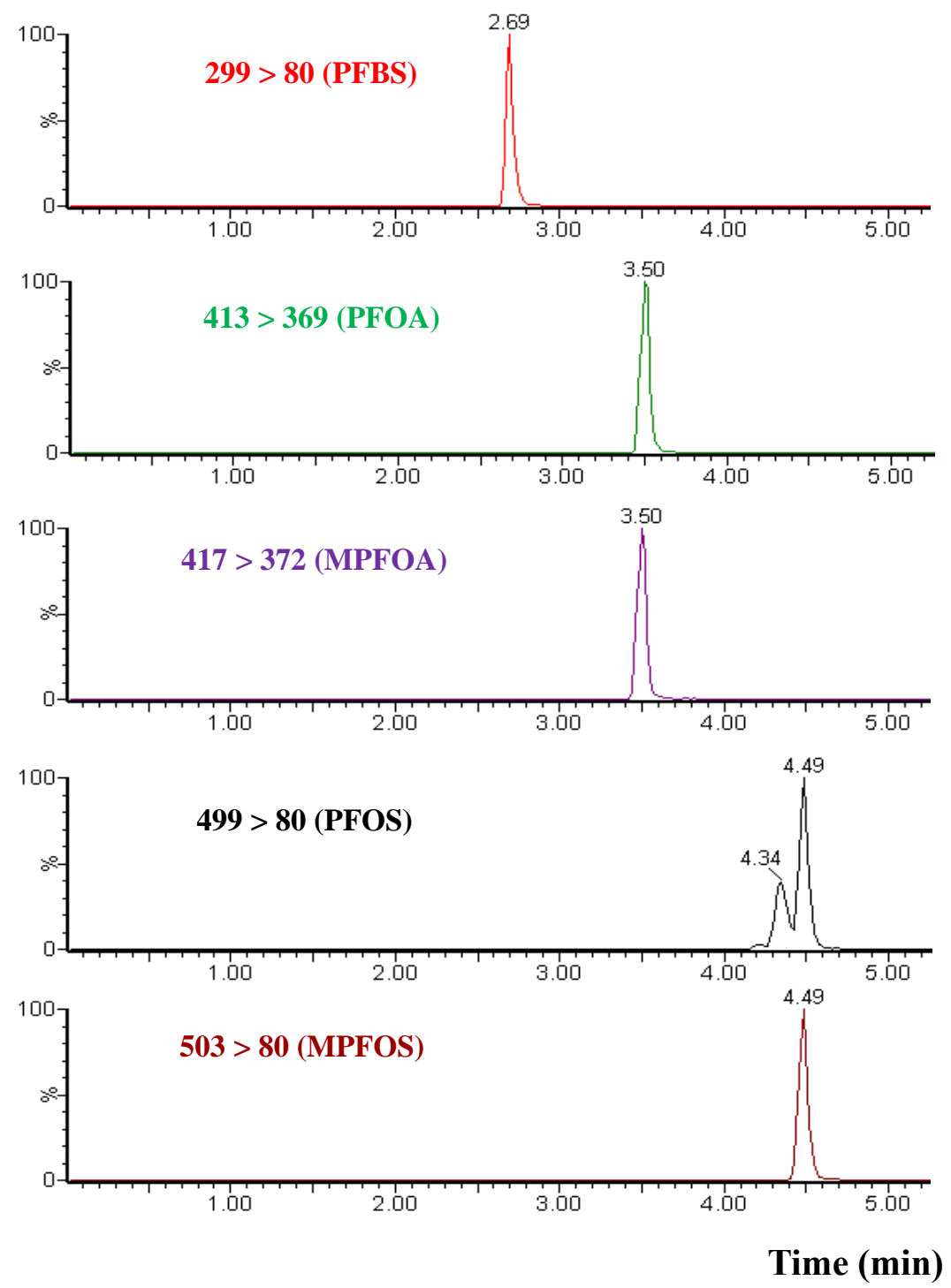

Fig. 1. LC-MS/MS chromatograms of PFOS, PFOA, PFBS and MPFOS, MPFOA with the respective ion transitions used for quantification and retention times. 

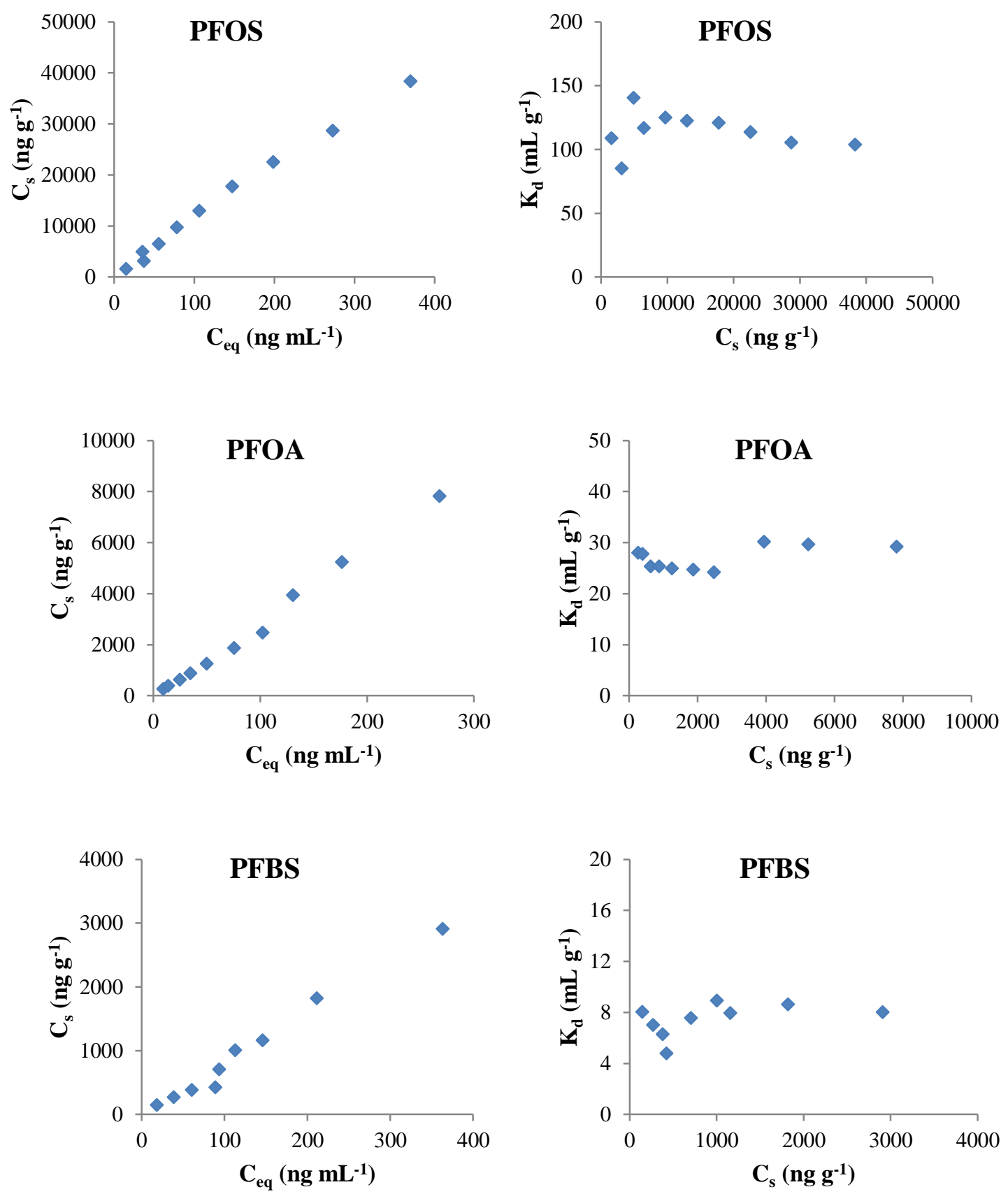

Fig. 2. Sorption isotherms of PFOS, PFOA and PFBS in the SL1 sludge: $\mathrm{C}_{\mathrm{s}}$ vs $\mathrm{C}_{\mathrm{eq}}$ and $\mathrm{K}_{\mathrm{d}} v s$. $\mathrm{C}_{\mathrm{s}}$ plots. 

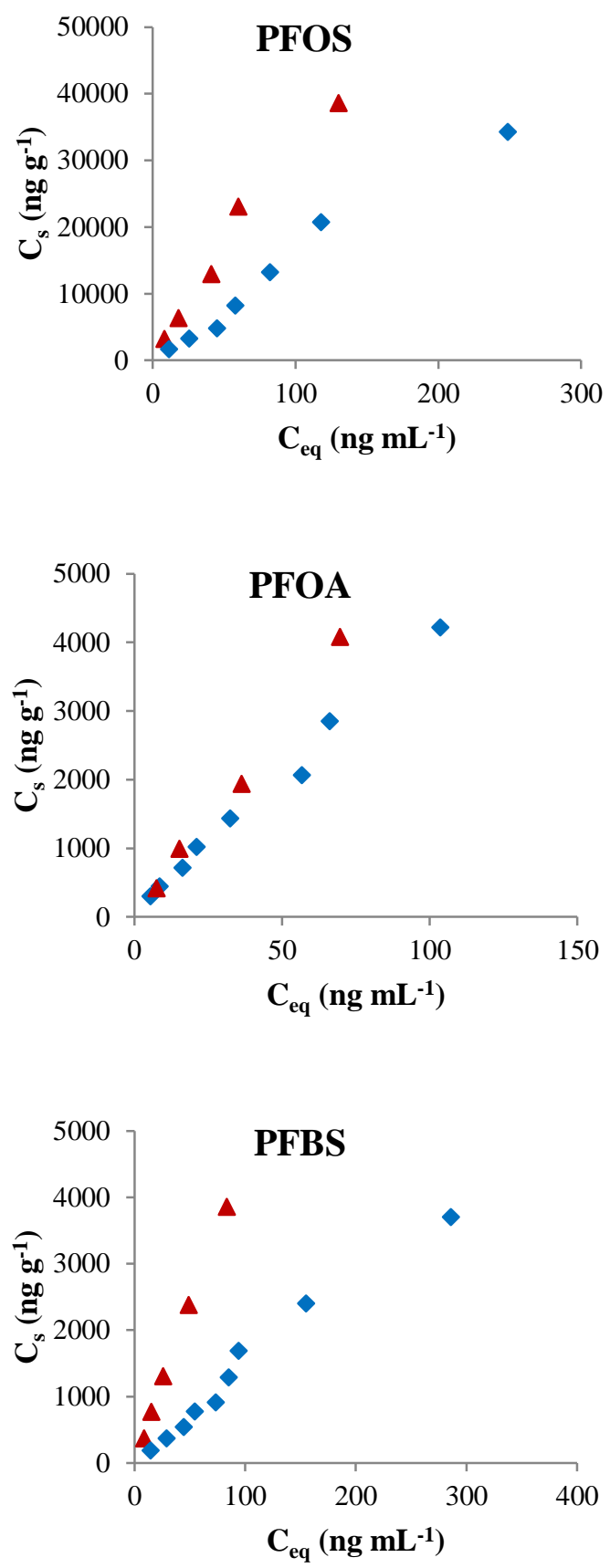

$\Delta$ Desorption $\bullet$ Sorption

Fig. 3. Sorption and desorption isotherms of PFOS, PFOA and PFBS in the SL2 sludge: $\mathrm{C}_{\mathrm{s}}$ $v s \mathrm{C}_{\text {eq }}$ plots. 


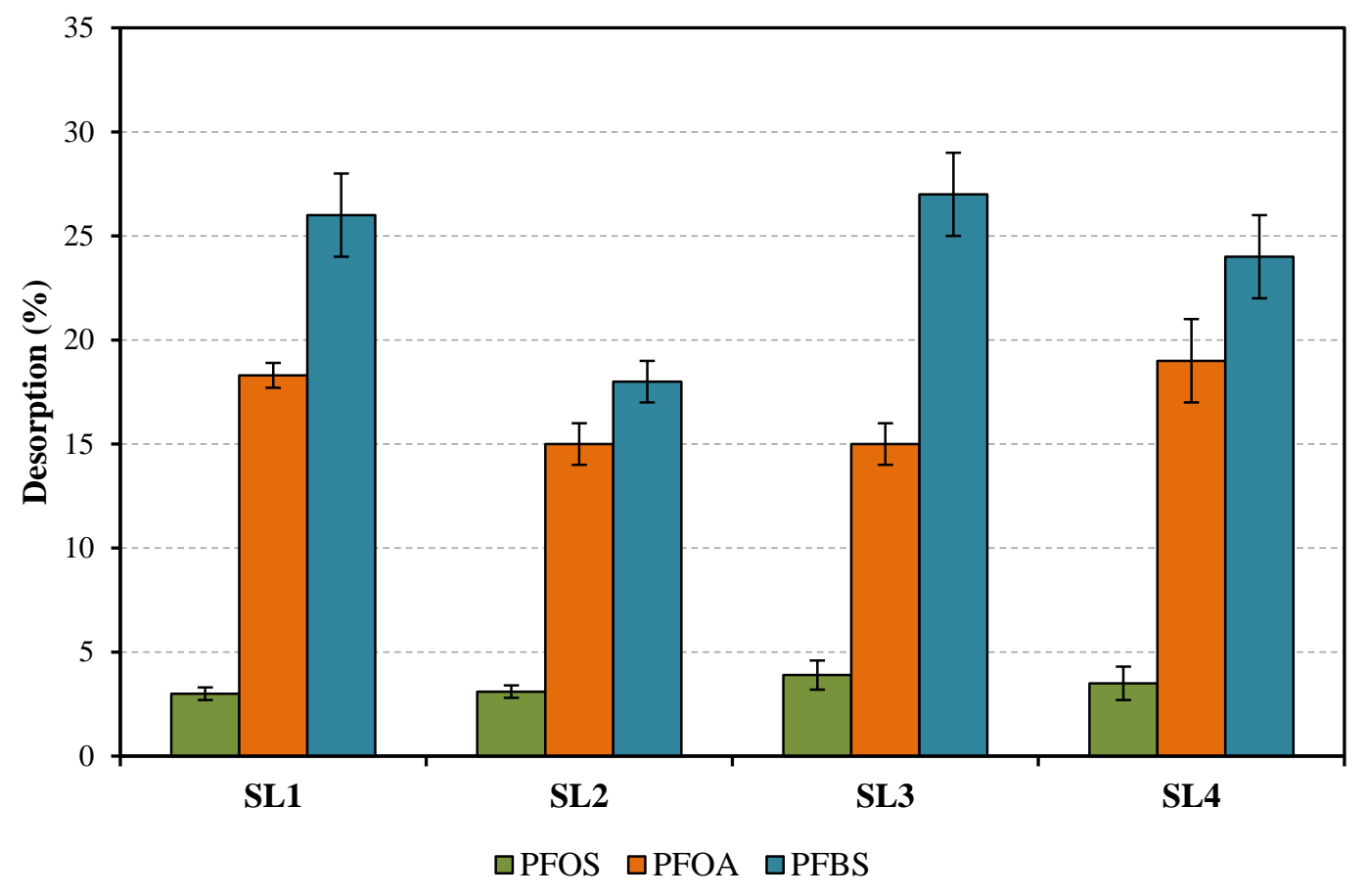

Fig. 4. Desorption yield (\%) of PFOS, PFOA and PFBS in the examined sludge samples. 
Table 1

Main physicochemical properties of selected PFCs.

\begin{tabular}{lllll}
\hline PFC name (molecular formula) & Abbreviation & Molecular weight $\left(\mathrm{g} \mathrm{mol}^{-1}\right)$ & Water solubility $\left(\mathrm{g} \mathrm{L}^{-1}\right)^{\mathrm{a}}$ & $\mathrm{pK}_{\mathrm{a}}^{\mathrm{a}}$ \\
\hline Perfluorooctanesulfonic acid $\left(\mathrm{C}_{8} \mathrm{HF}_{17} \mathrm{SO}_{3}\right)$ & PFOS & 500.1 & 0.57 & -3.3 \\
Perfluorooctanoic acid $\left(\mathrm{C}_{8} \mathrm{HF}_{15} \mathrm{O}_{2}\right)$ & PFOA & 414.0 & 3.4 & -0.26 \\
Perfluorobutanesulfonic acid $\left(\mathrm{C}_{4} \mathrm{HF}_{9} \mathrm{SO}_{3}\right)$ & PFBS & 300.1 & 46.2 & 4.59 \\
\hline
\end{tabular}

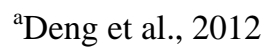




\section{Table 2}

Main sludge and sludge supernatant characteristics (mean value (SD); $n=3$ )

\begin{tabular}{|c|c|c|c|c|c|c|}
\hline \multirow[t]{2}{*}{ Sample } & \multicolumn{4}{|l|}{ Sludge } & \multicolumn{2}{|l|}{ Supernatant } \\
\hline & Dry matter $(\%)$ & $\mathrm{pH}$ & $\mathrm{OM}(\%)$ & $\mathrm{OC}(\%)$ & $\mathrm{Ca}+\mathrm{Mg}$ solution $\left(\mathrm{mmol} \mathrm{kg}^{-1}\right)$ & $\operatorname{DOC}\left(\mathrm{mg} \mathrm{kg}^{-1}\right)$ \\
\hline SL1 & $21.0(0.2)$ & $8.3(0.1)$ & $61.6(0.1)$ & $27.9(0.2)$ & $163(4)$ & $35900(60)$ \\
\hline SL2 & $17.2(0.1)$ & $8.4(0.1)$ & $62.5(0.8)$ & $28.2(0.3)$ & $145(4)$ & $21400(400)$ \\
\hline SL3 & $13.9(0.2)$ & $7.1(0.1)$ & $73.2(0.1)$ & $22.8(0.1)$ & $188(2)$ & $53000(1100)$ \\
\hline SL4 & $16.1(0.3)$ & $6.1(0.1)$ & $77.4(0.2)$ & $37.1(0.8)$ & $240(2)$ & $70000(2400)$ \\
\hline
\end{tabular}

OM: organic matter; OC: organic carbon; DOC: dissolved organic carbon 


\section{Table 3}

Sorption parameters (value, (SD)) obtained from the Freundlich and linear models for sorption isotherms of PFCs.

\begin{tabular}{|c|c|c|c|c|c|c|}
\hline \multirow[b]{2}{*}{ PFC } & \multirow[b]{2}{*}{ Sludge } & \multicolumn{2}{|c|}{ Experimental data } & \multicolumn{2}{|c|}{ Freundlich fitting } & \multirow{2}{*}{$\frac{\text { Linear fitting }}{\mathrm{K}_{\mathrm{d}, \text { linear }}\left(\mathrm{mL} \mathrm{g}^{-1}\right)}$} \\
\hline & & $\mathrm{K}_{\mathrm{d}, \min }\left(\mathrm{mL} \mathrm{g}^{-1}\right)$ & $\mathrm{K}_{\mathrm{d}, \max }\left(\mathrm{mL} \mathrm{g}^{-1}\right)$ & $\mathrm{N}$ & $\mathrm{K}_{\mathrm{F}}\left(n \mathrm{~g}^{(1-\mathrm{N})} \mathrm{mL}^{\mathrm{N}} \mathrm{g}^{-1}\right)$ & \\
\hline \multirow[t]{4}{*}{ PFOS } & SL1 & 85 & 140 & $1.0(0.1)$ & 129 & $104(3)$ \\
\hline & SL2 & 106 & 175 & $1.1(0.1)$ & 116 & $143(10)$ \\
\hline & SL3 & 143 & 252 & $1.0(0.1)$ & 161 & $171(7)$ \\
\hline & SL4 & 130 & 281 & $1.0(0.1)$ & 213 & $218(17)$ \\
\hline \multirow[t]{4}{*}{ PFOA } & SL1 & 24 & 30 & $1.0(0.1)$ & 25 & $30(1)$ \\
\hline & SL2 & 37 & 54 & $0.9(0.1)$ & 60 & $37(1)$ \\
\hline & SL3 & 36 & 53 & $1.1(0.1)$ & 32 & $50(2)$ \\
\hline & SL4 & 25 & 36 & $1.0(0.1)$ & 40 & $28(1)$ \\
\hline \multirow[t]{4}{*}{ PFBS } & SL1 & 5 & 9 & $1.0(0.1)$ & 6 & $8(1)$ \\
\hline & SL2 & 12 & 18 & $1.1(0.1)$ & 10 & $13(1)$ \\
\hline & SL3 & 2 & 7 & $1.0(0.1)$ & 5 & $5(1)$ \\
\hline & SL4 & 6 & 9 & $0.9(0.1)$ & 10 & $7(1)$ \\
\hline
\end{tabular}




\section{Table 4}

Desorption parameters (value (SE)) obtained from the Freundlich and linear equations for desorption isotherms of PFCs.

\begin{tabular}{|c|c|c|c|c|c|c|c|c|}
\hline \multirow[b]{2}{*}{ PFC } & \multirow[b]{2}{*}{ SL } & \multicolumn{2}{|c|}{ Experimental data } & \multicolumn{3}{|c|}{ Freundlich fitting } & \multicolumn{2}{|c|}{ Linear fitting } \\
\hline & & $\begin{array}{l}\mathrm{K}_{\mathrm{d} \text { des min }} \\
\left(\mathrm{mL} \mathrm{g}^{-1}\right)\end{array}$ & $\begin{array}{l}\mathrm{K}_{\mathrm{d} \text { des max }} \\
\left(\mathrm{mL} \mathrm{g}^{-1}\right)\end{array}$ & $\mathrm{N}_{\text {des }}$ & $\begin{array}{l}\mathrm{K}_{\mathrm{F}, \mathrm{des}} \\
\left.\left(\mathrm{ng}^{(1-\mathrm{N} \text { des }}\right) \mathrm{mL}^{\mathrm{N}_{\text {des }}} \mathrm{g}^{-1}\right)\end{array}$ & $\mathrm{K}_{\mathrm{F}, \mathrm{des}} / \mathrm{K}_{\mathrm{F}}$ & $\begin{array}{l}\mathrm{K}_{\mathrm{d}, \text { des,linear }} \\
\left(\mathrm{mL}^{-1}\right)\end{array}$ & $\mathrm{K}_{\mathrm{d}, \text { des,linear }} / \mathrm{K}_{\mathrm{d}, \text { linear }}$ \\
\hline \multirow[t]{4}{*}{ PFOS } & SL1 & 318 & 397 & $1.0(0.1)$ & 379 & 2.9 & $332(8)$ & 3.2 \\
\hline & SL2 & 296 & 382 & $0.9(0.1)$ & 458 & 3.9 & $299(1)$ & 2.1 \\
\hline & SL3 & 309 & 342 & $0.9(0.1)$ & 421 & 2.6 & $335(9)$ & 2.0 \\
\hline & SL4 & 349 & 479 & $0.9(0.1)$ & 697 & 3.3 & $367(31)$ & 1.7 \\
\hline \multirow[t]{4}{*}{ PFOA } & SL1 & 33 & 56 & $1.0(0.1)$ & 48 & 1.9 & $49(3)$ & 1.6 \\
\hline & SL2 & 53 & 67 & $1.0(0.1)$ & 53 & 0.9 & $67(4)$ & 1.8 \\
\hline & SL3 & 56 & 67 & $1.0(0.1)$ & 65 & 2.0 & $62(4)$ & 1.2 \\
\hline & SL4 & 42 & 58 & $1.0(0.2)$ & 58 & 1.5 & $50(5)$ & 1.8 \\
\hline \multirow[t]{4}{*}{ PFBS } & SL1 & 27 & 36 & $1.1(0.1)$ & 23 & 3.8 & $31(2)$ & 3.9 \\
\hline & SL2 & 41 & 50 & $1.0(0.1)$ & 43 & 4.3 & $46(1)$ & 3.5 \\
\hline & SL3 & 26 & 27 & $1.0(0.1)$ & 29 & 5.8 & $25(1)$ & 5.0 \\
\hline & SL4 & 36 & 45 & $0.9(0.1)$ & 47 & 4.7 & $40(2)$ & 5.7 \\
\hline
\end{tabular}




\title{
Supplementary Information
}

\section{Sorption of perfluoroalkyl substances in sewage sludge}

\author{
Jelena Milinovic $^{\mathrm{a}}$, Silvia Lacorte ${ }^{\mathrm{b}}$, Anna Rigol $^{\mathrm{a},{ }^{*}, \text { Miquel Vidal }^{\mathrm{a}}}$ \\ ${ }^{\mathrm{a}}$ Department of Analytical Chemistry, University of Barcelona, Martí i Franquès 1-11, \\ 08028 Barcelona, Catalonia, Spain, \\ ${ }^{\mathrm{b}}$ Department of Environmental Chemistry, IDAEA-CSIC, Jordi Girona 18-26, 08034 \\ Barcelona, Catalonia, Spain
}




\section{Table S1}

Parameters of multiple reaction monitoring for PFASs analysis by LC-MS/MS

\begin{tabular}{llll}
\hline PFAS & Transition ions $(\mathrm{m} / \mathrm{z})$ & Cone voltage $(\mathrm{V})$ & Collision energy $(\mathrm{eV})$ \\
\hline MPFOS & $503 \rightarrow 80$ & 52 & 39 \\
& $503 \rightarrow 99$ & & \\
PFOS & $499 \rightarrow 80$ & 50 & 42 \\
& $499 \rightarrow 99$ & 17 & 10 \\
MPFOA & $417 \rightarrow 372$ & & 20 \\
PFOA & $413 \rightarrow 169$ & 19 & 11 \\
& $413 \rightarrow 369$ & & 29 \\
PFBS & $299 \rightarrow 80$ & 50 & 26 \\
\hline
\end{tabular}



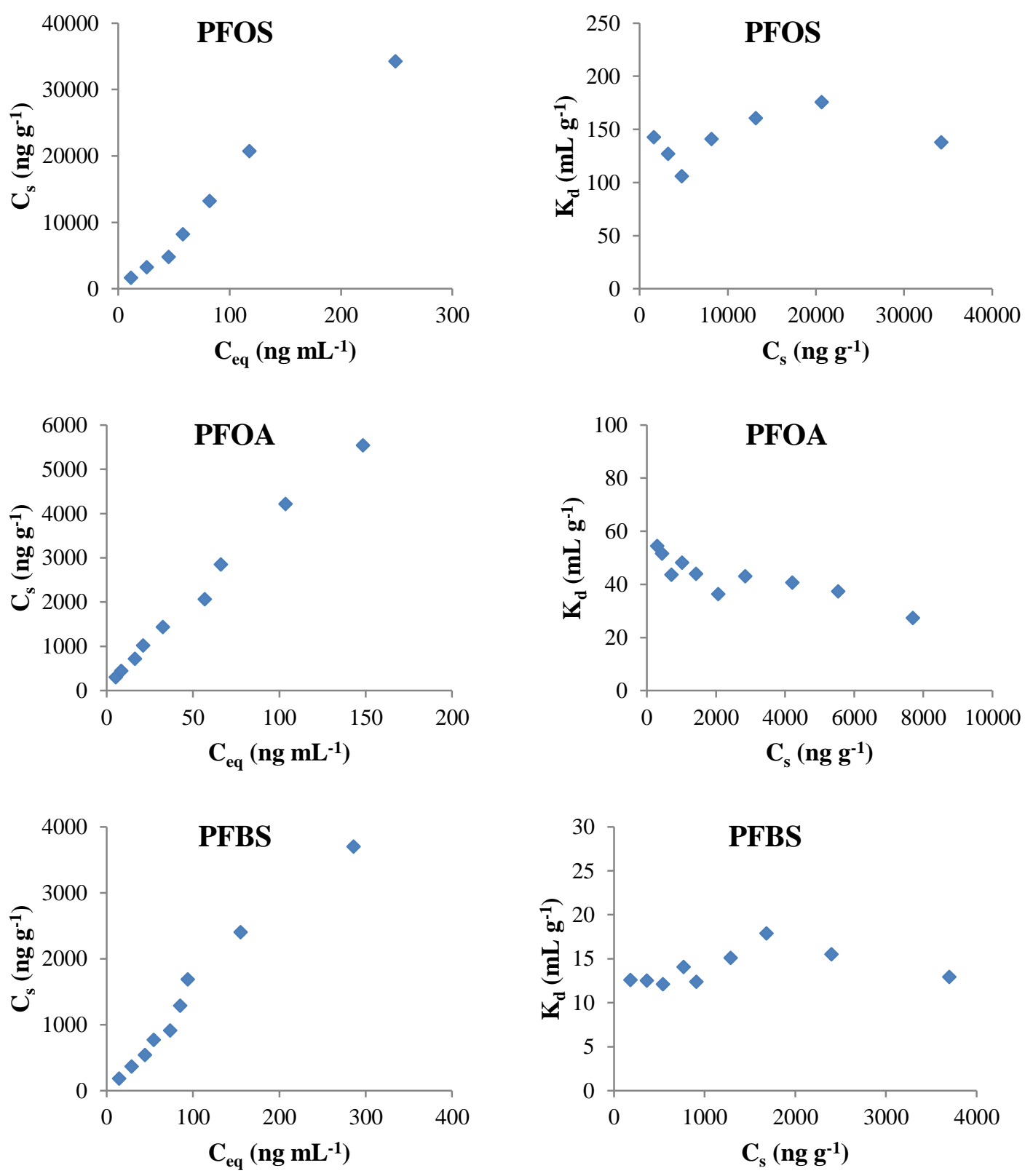

Fig. S1. Sorption isotherms of PFOS, PFOA and PFBS in the SL2 sludge: $\mathrm{C}_{\mathrm{s}} v s . \mathrm{C}_{\mathrm{eq}}$ and $\mathrm{K}_{\mathrm{d}} v s . \mathrm{C}_{\mathrm{s}}$ plots. 

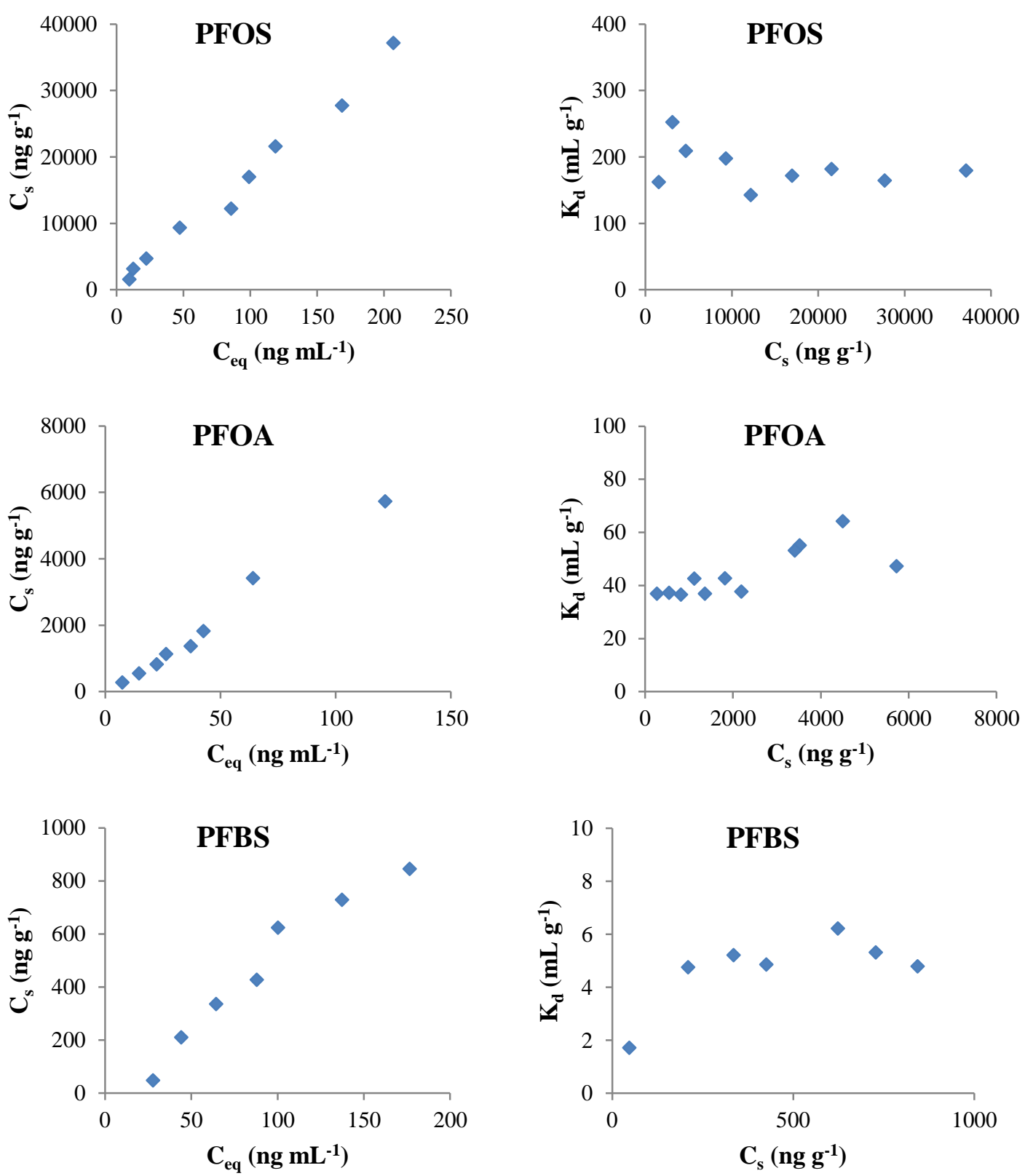

Fig. S2. Sorption isotherms of PFOS, PFOA and PFBS in the SL3 sludge: $\mathrm{C}_{\mathrm{s}} v s . \mathrm{C}_{\mathrm{eq}}$ and $\mathrm{K}_{\mathrm{d}} v s . \mathrm{C}_{\mathrm{s}}$ plots. 

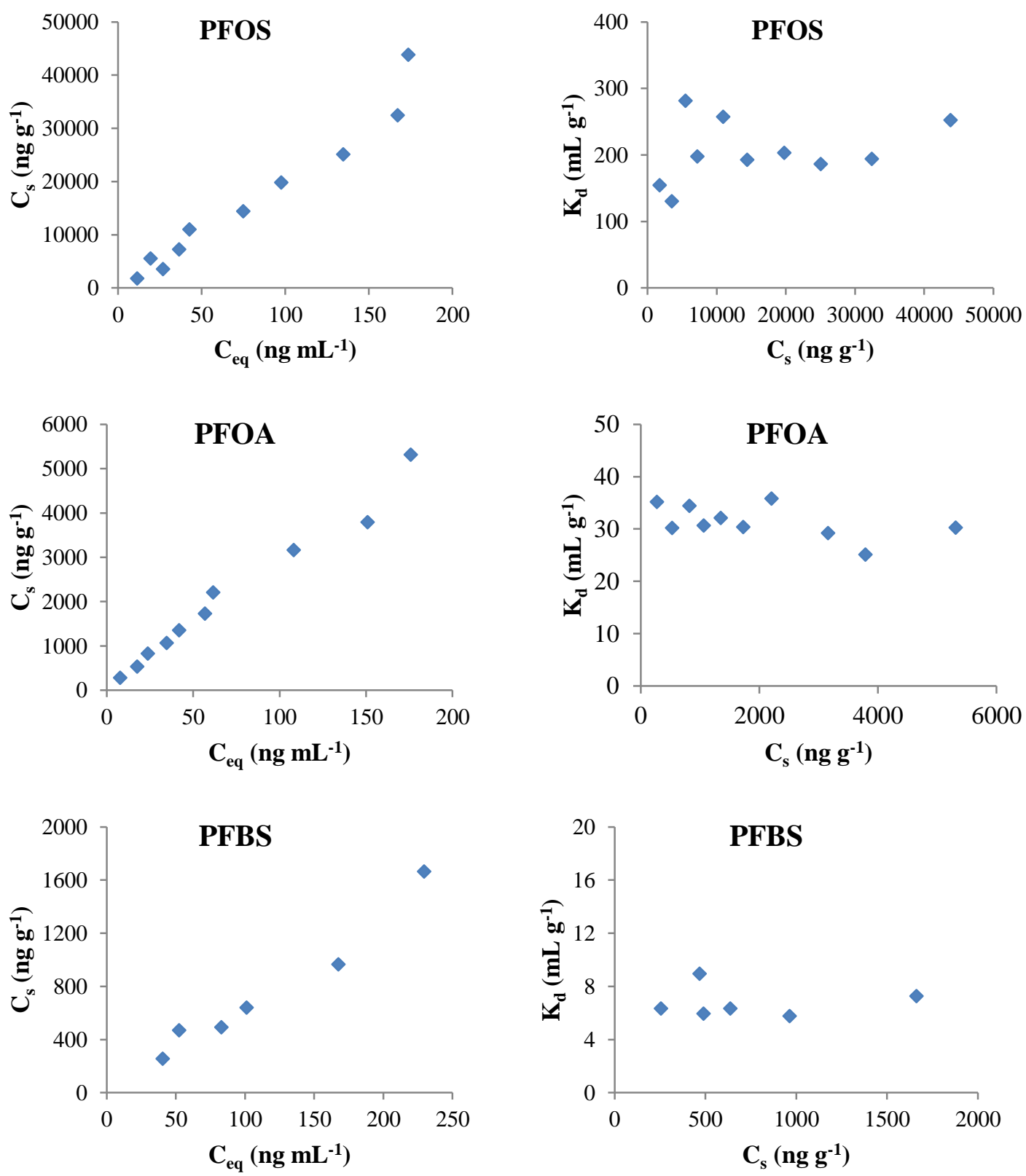

Fig. S3. Sorption isotherms of PFOS, PFOA and PFBS in the SL4 sludge: $\mathrm{C}_{\mathrm{s}} v s . \mathrm{C}_{\mathrm{eq}}$ and $\mathrm{K}_{\mathrm{d}} v s . \mathrm{C}_{\mathrm{s}}$ plots. 

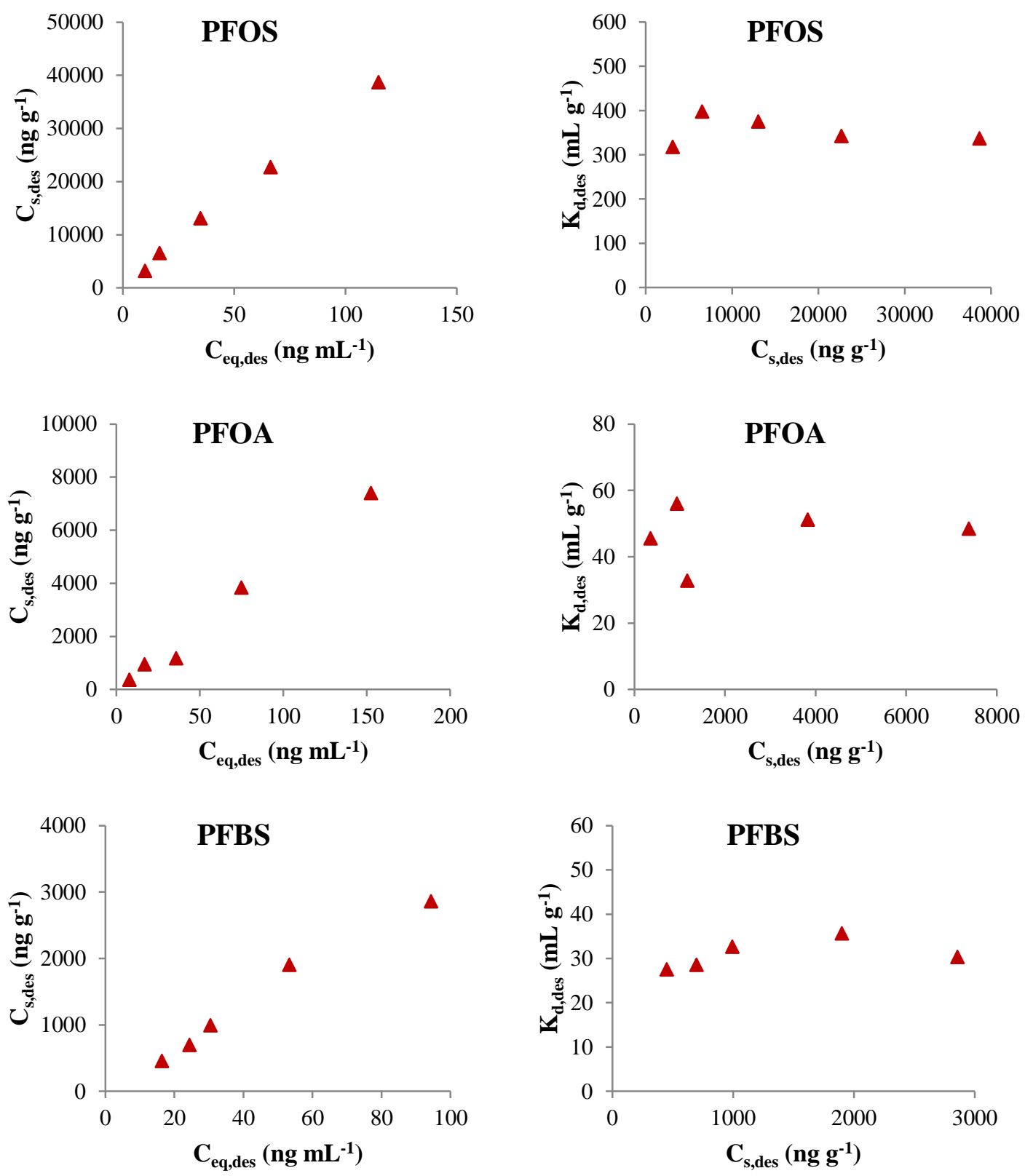

Fig. S4. Desorption isotherms of PFOS, PFOA and PFBS in the SL1 sludge: $\mathrm{C}_{\mathrm{s}, \mathrm{des}} v \boldsymbol{s}$. $\mathrm{C}_{\text {eq,des }}$ and $\mathrm{K}_{\mathrm{d} \text {,des }} v s . \mathrm{C}_{\mathrm{s} \text {,des }}$ plots. 

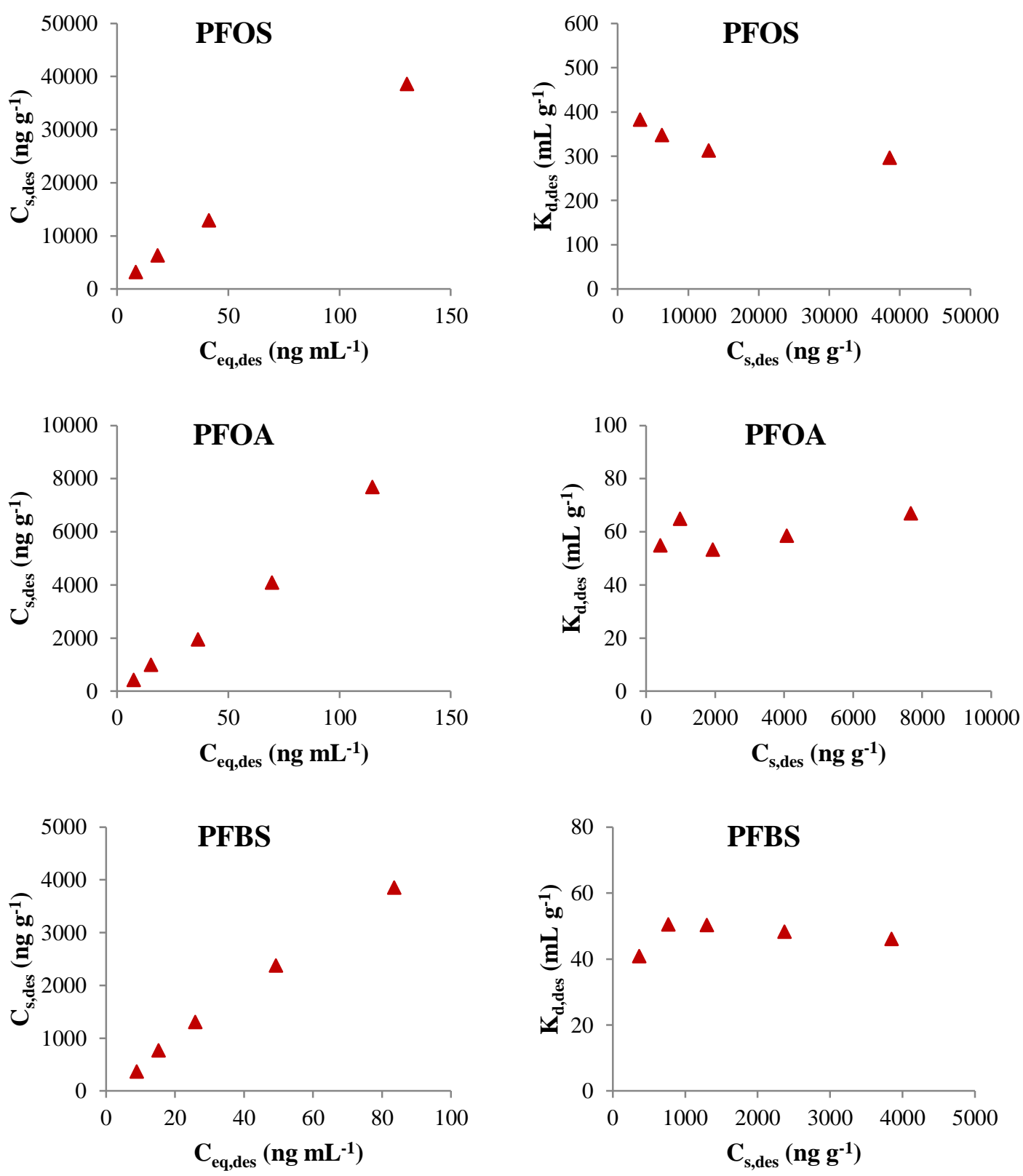

Fig. S5. Desorption isotherms of PFOS, PFOA and PFBS in the SL2 sludge: $\mathrm{C}_{\mathrm{s}, \mathrm{des}} v \boldsymbol{s}$. $\mathrm{C}_{\mathrm{eq}, \mathrm{des}}$ and $\mathrm{K}_{\mathrm{d} \text {,des }} v s . \mathrm{C}_{\mathrm{s} \text {,des }}$ plots. 

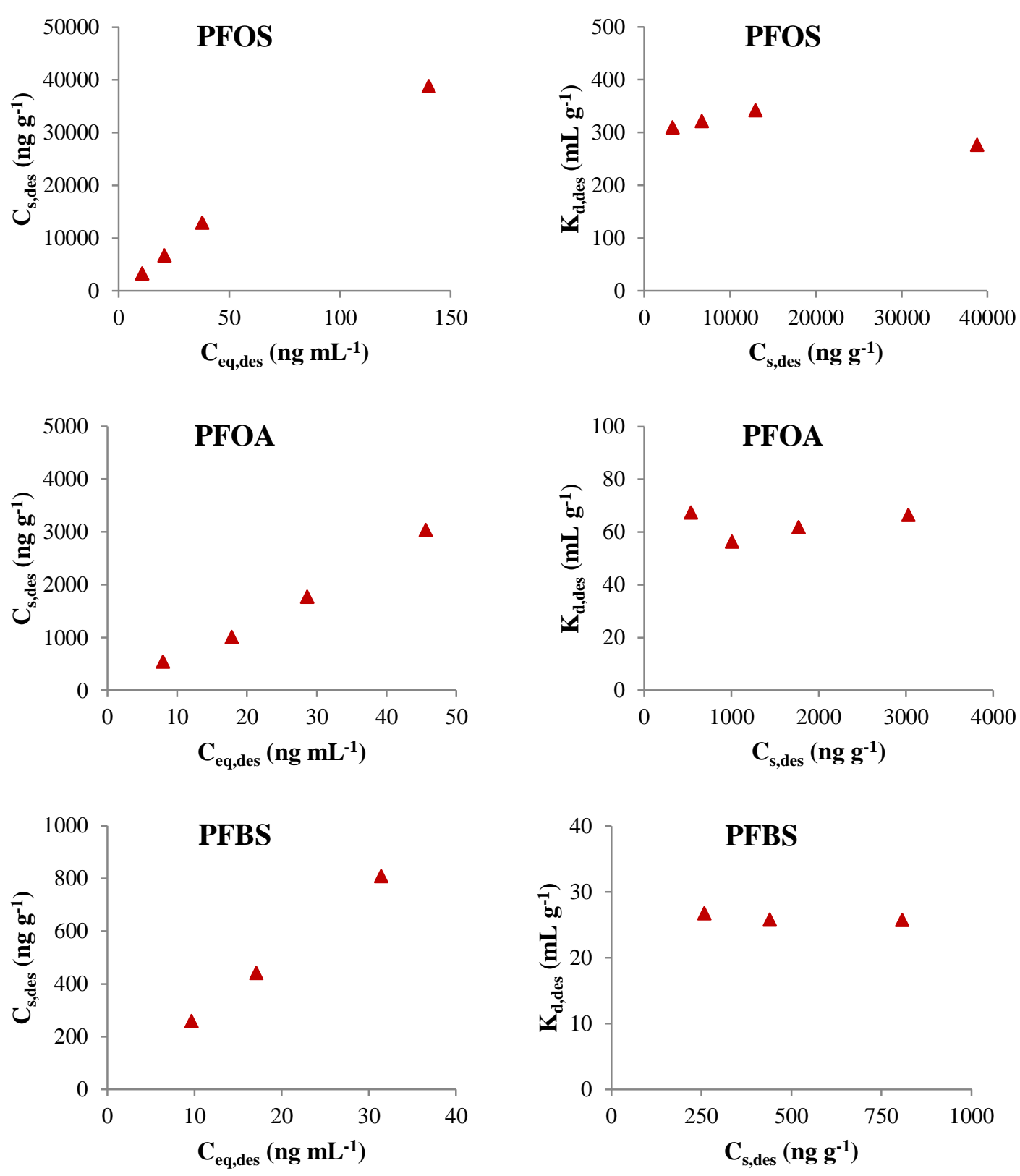

Fig. S6. Desorption isotherms of PFOS, PFOA and PFBS in the SL3 sludge: $\mathrm{C}_{\mathrm{s}, \mathrm{des}} v \boldsymbol{s}$. $\mathrm{C}_{\mathrm{eq}, \mathrm{des}}$ and $\mathrm{K}_{\mathrm{d} \text {,des }} v s . \mathrm{C}_{\mathrm{s}, \mathrm{des}}$ plots. 

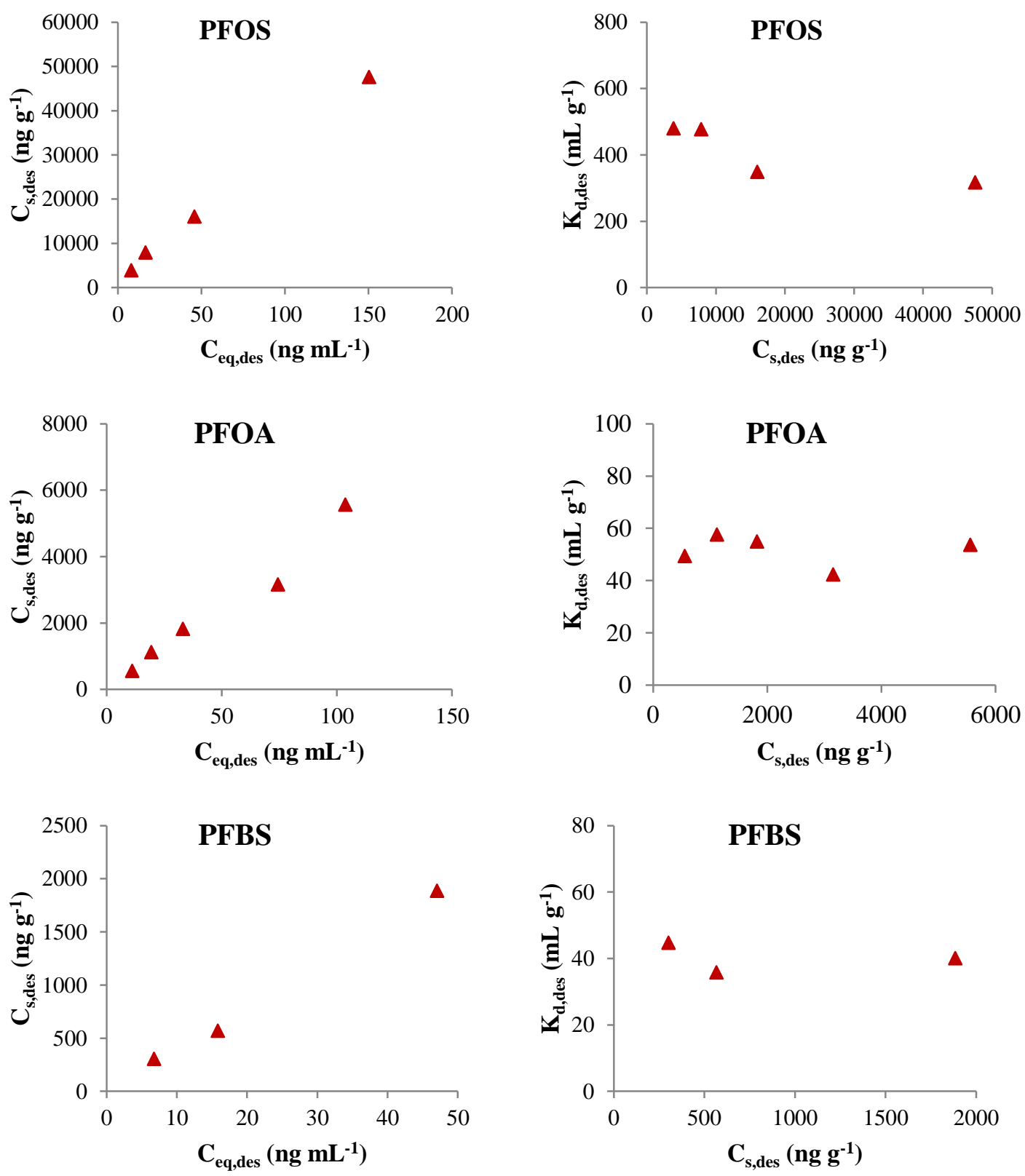

Fig. S7. Desorption isotherms of PFOS, PFOA and PFBS in the SL4 sludge: $\mathrm{C}_{\mathrm{s}, \mathrm{des}} v$. $\mathrm{C}_{\mathrm{eq}, \mathrm{des}}$ and $\mathrm{K}_{\mathrm{d}, \mathrm{des}} v s . \mathrm{C}_{\mathrm{s}, \mathrm{des}}$ plots. 